\title{
Identificación molecular de Brucella abortus en nódulos linfáticos de bovinos faenados en Loja
}

\section{Molecular identification of Brucella abortus isolated from lymph nodes of cattle slaughtered in Loja}

\author{
Franklin Román-Cárdenas ${ }^{1 *}$, Pablo Ramón-Contento² \\ ${ }^{1}$ Universidad Nacional de Loja, Centro de Biotecnología, Ciudadela universitaria, Loja, Ecuador. \\ $凶$ franklinroman11@gmail.com \\ https://orcid.org/0000-0003-3669-7009 \\ ${ }^{2}$ Universidad Técnica Particular de Loja, Departamento de Ciencias Biológicas, Loja, Ecuador. \\ 凶aramon@utpl.edu.ec \\ https://orcid.org/0000-0003-4123-4172
}

\begin{abstract}
Resumen
La brucelosis es una enfermedad infecciosa causada por microorganismos del género Brucella que afectan a diferentes especies de mamíferos; la cual provoca aborto, epididimitis, vesiculitis, nacimiento de terneros débiles, merma en la producción de leche, infertilidad y subfertilidad en vacas y toros. La enfermedad por ser zoonótica se considera un problema de salud pública. El objetivo de este diagnóstico fue identificar Brucella abortus mediante la reacción en cadena de la polimerasa. Se logró amplificar un fragmento de $223 \mathrm{pb}$ de la región del gen BCSP31 como fuente de ADN, obtenido a partir de muestras de nódulos linfáticos de la región cervical, pulmonar, bronquial, retrofaríngea y mediastínica. Se analizaron 115 animales faenados en un camal de Loja en el año 2015. La edad de los animales osciló entre 4 y 6 años. En el 14,8 \% (17) de los animales faenados se registró positividad a la prueba; aunque la presencia de la bacteria se observó con mayor frecuencia en las regiones cervical, bronquial y retrofaríngea. Con el presente estudio mediante la prueba molecular de PCR se demuestra la presencia de la bacteria Brucella abortus al encontrarla en nódulos linfáticos de animales faenados en el cantón Loja.
\end{abstract}

Palabras clave: Brucella spp., aborto, zoonosis, PCR, diagnóstico molecular.

\begin{abstract}
Brucellosis is an infectious disease caused by microorganisms of the genus Brucella that affect different species of mammals. The bacteria cause abortion, epididymitis, vesiculitis, birth of weak calves, the decrease in milk production, and infertility in cows and bulls. The disease is a zoonosis and is considered a public health problem. The objective of this work was to identify Brucella abortus by the Polymerase Chain Reaction. It was possible through the amplification of a fragment of $223 \mathrm{bp}$ of the BCSP31 gene region, as DNA source, obtained from lymph nodes of the region cervical, pulmonary, bronchial, retropharyngeal, and mediastinal. One hundred and fifteen samples from animals slaughtered at Loja city abattoir in 2015 were analyzed. In 14.8\% (17) of the slaughtered animals, the test was positive; although the presence of the bacteria was observed more frequently in the cervical, bronchial and retropharyngeal regions. The age of the positive animals ranged between 4 and 6 years. With the present study, it was confirmed the presence of the bacterium Brucella abortus through the molecular PCR test obtained from lymph nodes of slaughtered animals in the Loja canton.
\end{abstract}

Keywords: Brucella spp., abortion, zoonosis, PCR, molecular diagnosis. 


\section{Introducción}

La brucelosis es una enfermedad antigua que se remonta a más de siete siglos a. de $\mathrm{C}$. según estudios realizados en muestras de antiguos egipcios donde se encontró evidencia de lesiones osteoarticulares comunes de la brucelosis (Pappas \& Papadimitriou, 2007). Cinco de las nueve especies de brucela conocidas pueden infectar a los humanos, y entre las más invasivas se encuentran $B$. militensis, seguida de $B$. suis, B. abortus y B. canis (Acha \& Szyfres, 2003). La brucelosis es causada por la bacteria brucela, que es una infección común que llega a afectar a humanos y animales (Yousefi-Nooraie et al., 2012). Es endémica en países de la cuenca mediterránea, Asia occidental, Golfo Pérsico, partes de África central, Norteamérica, América Latina y leve incidencia en Oceanía (Pappas et al., 2006). Entre los años 2006 y 2015 a nivel mundial, se registraron 924.121 casos de brucelosis por Brucella abortus en ganado bovino, con mayor presencia en América (561.990 casos) (Organización Mundial de Sanidad Animal [OIE], 2017).

Es una de las zoonosis más comunes con más de medio millón de casos de personas afectadas y reportados anualmente (Ran et al., 2019). Se transmite a las personas por contacto directo con animales o a través de fluidos como orina, sangre, semen, secreciones vaginales, heces, luego de abortos o partos a término por fluidos uterinos y la placenta (Carlosama, 2013; Díaz, 2013), por aerosoles infectantes, y consumo de leche y subproductos lácteos no pasteurizados. Las personas con mayor predisposición a contraer la enfermedad son profesionales que están expuestos al ganado infectado o sus productos; veterinarios, laboratoristas, trabajadores de frigoríficos, y de campo, es una de las enfermedades más frecuentes en los mataderos (Peña, 2011). En las comunidades rurales la brucelosis humana tiene una alta incidencia debido a la estrecha convivencia entre humanos y animales. En las áreas en que la brucelosis se presenta de manera endémica el rango varía entre $<0,01$ a $>200$ por cada 100.000 habitantes (Luna, 2015). En todo el mundo se reportan más de 500.000 casos de brucelosis humana cada año (Carlosama, 2013). La Organización Mundial de la Salud (OMS) informa que 4 de cada 10 habitantes viven en zonas donde se reconoce la presencia de la enfermedad (Paredes, 2012). Los casos de brucelosis humana contabilizados son menores a su incidencia real, debido a que las personas no notifican y a la existencia de casos asintomáticos. En la provincia de Santo Domingo-Ecuador, Cuenca (2013) reportó la presencia de $1,43 \%$ de brucelosis humana. El contagio de brucelosis es un alto riesgo para la salud humana; sus síntomas característicos son fiebre continua, intermitente o irregular, de duración variable (10 a 30 días), cefalea, fatiga, diaforesis, mialgias, pérdida de peso, anorexia, malestar generalizado, con o sin signos de localización como: artritis/espondilitis, meningitis, endocarditis, orquitis/ epididimitis (Ministerio de Salud Pública de la Nación [MSPN], 2013), y en los casos en que la enfermedad se agudiza puede llevar a la muerte (García et al., 2014).

La brucelosis bovina es una enfermedad de declaración obligatoria, de acuerdo con lo sugerido por la OIE (Resolución DAJ-2013461-0201.0214). Con el fin de evitar riesgos ocupacionales en sectores donde exista brucelosis de cualquier especie, se impone el decomiso de glándulas mamarias, órganos genitales, ganglios seleccionados y decomiso total en lesiones generalizadas de los bovinos (Resolución 0197).

De esta enfermedad no se dispone de información actualizada en la provincia de Loja, por lo que el trabajo que se realiza al interno de los camales resulta de vital importancia para vigilar las condiciones de higiene y prevenir enfermedades profesionales. (Resolución DAJ-2013461-0201.0214), ya que es una zoonosis extremadamente infecciosa para el ser humano. Por tanto, el objetivo de la presente investigación es confirmar, a través de la prueba molecular de reacción en cadena de la polimerasa, la presencia de la bacteria Brucella abortus, en nódulos linfáticos de bovinos faenados en un camal de Loja. Para ello se formularon las siguientes hipótesis: (i) existen nódulos linfáticos de ciertas regiones con mayor predisposición a la presencia de la bacteria, (ii) la detección de la brucelosis está en relación con la raza y el sexo del bovino.

\section{Materiales y métodos}

\subsection{Colección de la muestra}

Durante un período de tiempo de seis semanas, en el camal de Loja se registró un total de 1.554 bovinos faenados, de esta población de tomó una muestra aleatoria de 115 ( 78 machos y 37 hembras) con edad promedio de 4,5 años. La selección del tamaño mínimo de muestra para estimar la proporción de afección de la enfermedad se realizó con un nivel de confianza del $95 \%$, una prevalencia esperada de brucelosis del $3 \%$ (Escobar, 2017), y un margen de error muestral 
de $3 \%$. Para el análisis de laboratorio se recolectaron 575 muestras de nódulos linfáticos de la cabeza, los retrofaríngeos laterales, del cuello, los cervicales superficiales, de la cavidad torácica, pulmonares y bronquiales, y de la cavidad pelviana el inguinofemoral. El último sitio de estancia de los animales correspondió a las parroquias urbanas y rurales del cantón Loja: San Lucas, El Sagrario, Sucre, El Valle, Santiago, Yangana, San Sebastián, Jimbilla, Chantaco Gualel, Taquil, Malacatos; así también de los cantones Amaluza, Quilanga y de los sectores El Tambo y Numbala, pertenecientes a la provincia de Zamora Chinchipe.

Para evaluar la distribución de la bacteria según los nódulos linfáticos, se utilizó la prueba de bondad de ajuste chi-cuadrado basada en la diferencia entre las frecuencias observadas y las frecuencias esperadas bajo un comportamiento aleatorio. Para contrastar la segunda hipótesis e identificar si existe relación entre la positividad de la prueba PCR y las tres razas del bovino consideradas en el estudio, se utilizó una prueba chi-cuadrado sobre los residuos estandarizados de Pearson expresados como: $d_{i j}=\left(O_{i j}-E_{i j}\right) / \sqrt{ } E_{i j}$, donde $O_{i j}$ representan las frecuencias observadas de individuos en la fila $i$ (raza) y columna $j$ (prueba PCR) de la tabla de contingencia, $E_{i j}$ las frecuencias esperadas respectivamente. La suma de los cuadrados de los residuos estandarizados genera el valor del estadístico de prueba chi-cuadrado.
Las pruebas estadísticas indicadas anteriormente se realizaron con un nivel de significación del $5 \%$. Todos los cálculos estadísticos se realizaron en el software R (R Core Team, 2020).

\subsection{Detección de Brucella abortus mediante PCR}

Para la extracción de ADN se pesó $25 \mathrm{mg}$ de cada uno de los tejidos, posteriormente se maceraron en nitrógeno líquido, los tejidos pulverizados se colocaron en tubos eppendor de $1,5 \mathrm{~mL}$, para cada muestra se empleó el kit de extracción de ADN de la empresa Promega, según las indicaciones del fabricante, el ADN obtenido se cuantificó en el espectrofotómetro Nano Drop 2000 seleccionándose las muestras con concentraciones iguales o superiores a $10 \mathrm{ng} / \mu \mathrm{L}$, en el mismo equipo se determinó el índice de pureza de la muestra A260/A280 utilizándose las muestras con rango igual o superior a 1,8. La PCR se optimizó dirigida a la amplificación de un fragmento de 223 pb de la secuencia del gen BCSP31, que codifica para una proteína de membrana externa de $31 \mathrm{kDa}$ específica de $B$. abortus, que se conserva en todas las especies de Brucella (Mayfield et al., 1988). se usaron los primeros B4 (5'-TGGCTCGGTTGCCAATATCAA-3') y B5 (5'-CGCGCTTGCCTTTCAGGTCTG-3'), la preparación de la PCR se realizó a $25 \mu \mathrm{L}$ con base en los parámetros que se describen en la Tabla 1.

Tabla 1. Cantidades requeridas de los reactivos para la preparación de la PCR

\begin{tabular}{|c|c|c|c|c|}
\hline Reactivo & $\begin{array}{c}\text { Concentración } \\
\text { stock }\end{array}$ & $\begin{array}{l}\text { Concentración } \\
\text { requerida }\end{array}$ & $\begin{array}{l}\text { Mix } \\
(\mu L)\end{array}$ & $\mathrm{xn} * 1$ \\
\hline Buffer & $10 \mathrm{X}$ & $1 \mathrm{x}$ & $2,5 \mu \mathrm{L}$ & \\
\hline dNTPs & $10 \mathrm{mM}$ & $0,2 \mathrm{mM}$ & $0,5 \mu \mathrm{L}$ & \\
\hline $\mathrm{MgCl} 2$ & $25 \mathrm{mM}$ & $1,5 \mathrm{mM}$ & $1,5 \mu \mathrm{L}$ & \\
\hline Primer $1(\mathrm{~F})$ & $25 \mu \mathrm{M}$ & $1 \mu \mathrm{M}$ & $0,5 \mu \mathrm{L}$ & \\
\hline Primer 2 (R) & $25 \mu \mathrm{M}$ & $1 \mu \mathrm{M}$ & $0,5 \mu \mathrm{L}$ & \\
\hline Taq Polimerasa & $5 \mathrm{U} / \mu \mathrm{L}$ & $1 \mathrm{U}$ & $0,2 \mu \mathrm{L}$ & $5,7 \mu \mathrm{L}$ \\
\hline $\mathrm{ADN}$ & $50 \mathrm{ng} / \mu \mathrm{L}$ & $100 \mathrm{ng} / \mu \mathrm{L}$ & $2 \mu \mathrm{L}$ & $2 \mu \mathrm{L}$ \\
\hline \multirow[t]{2}{*}{$\mathrm{H} 2 \mathrm{O}$} & & & $17,3 \mu \mathrm{L}$ & $17,3 \mu \mathrm{L}$ \\
\hline & & & & $25 \mu \mathrm{L}$ \\
\hline
\end{tabular}


Los parámetros de amplificación fueron: desnaturalización inicial $95{ }^{\circ} \mathrm{C}$ por 3 minutos, 35 ciclos de desnaturalización a $95^{\circ} \mathrm{C}$ por 1 minuto, alineamiento a $64{ }^{\circ} \mathrm{C}$ por 1 minuto y extensión a $72{ }^{\circ} \mathrm{C}$ por 1 minuto; y con una extensión final a $72{ }^{\circ} \mathrm{C}$ por 5 minutos, la amplificación se la realizó en el termociclador Applied Biosystems Veriti Thermal Cycler.

Para la electroforesis, se preparó un gel de agarosa con TBE al 1X, agarosa al 1,5\%, y adicionando 0,7 $\mu$ lde Syber safe, se utilizó un marcador de peso molecular de $100 \mathrm{pb}$ y los productos de PCR $0,8 \mu 1$ de cada uno se combinaron con 0,2 $\mu \mathrm{L}$ de blue juice para ser depositados en cada pocillo del gel. Se programó la fuente de poder y se realizó la corrida durante $60 \mathrm{~min}$ a 80 voltios. La visualización del gel de electroforesis se realizó mediante el sistema de documentación ENDU$\mathrm{RO}^{\mathrm{TM}}$ GDS Touch.

\section{Resultados}

\subsection{Identificación de Brucella abortus en nódulos linfáticos de bovinos faenados en la ciudad de Loja}

De los 115 bovinos faenados muestreados el $14,8 \%$ (17) resultaron positivos y el $85,2 \%$ (98) negativos a la prueba, la edad de los animales positivos osciló entre 4 y 6 años. Se observó en cinco muestras (muestra Nro.12-23-24-26-43) la amplificación del fragmento de $223 \mathrm{pb}$ de la secuencia del gen BCSP31, la misma amplificación que la del control positivo $(+)$ (Figura 1).
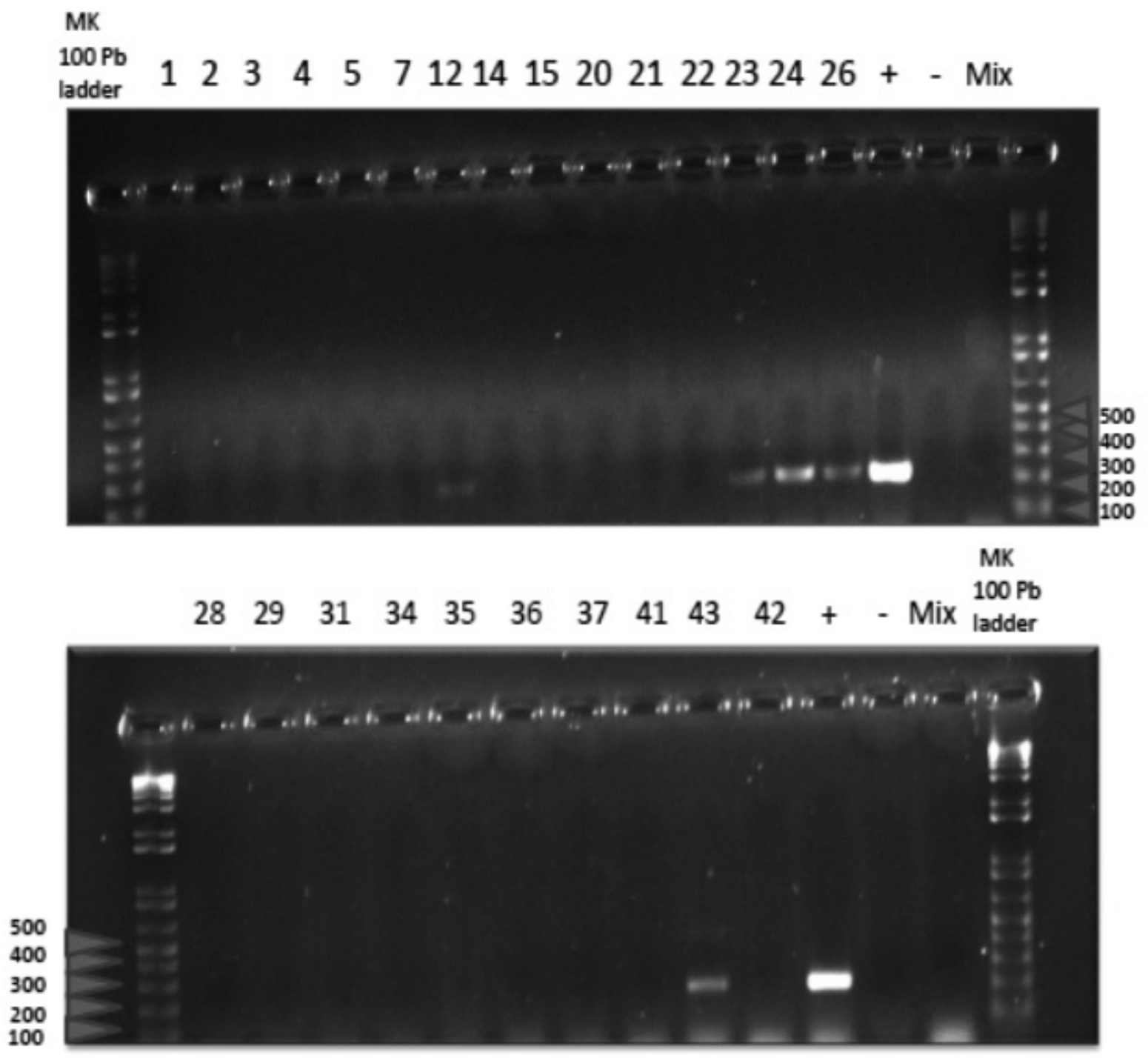

Figura 1. Amplificación del fragmento de 223 pb de la secuencia del gen BCSP31. 
3.2. Detección de ADN de Brucella abortus por localización de los nódulos linfáticos

En un mismo animal faenado, la presencia de la bacteria no fue detectada por igual en los nódulos linfáticos de las cinco regiones investigadas (Tabla $2)$; sin embargo, estas diferencias no fueron significativas $\left(\chi^{2}=1,5 ;\right.$ g.1. $\left.=4 ; p=0,8266\right)$.

Tabla 2. Número de casos positivos de Brucella abortus por región del nódulo linfático.

\begin{tabular}{|c|c|c|c|c|c|c|c|}
\hline \multicolumn{6}{|c|}{ Nódulos linfáticos de las regiones investigadas positivos a PCR } & \multirow{2}{*}{$\begin{array}{c}\text { Total } \\
\text { nódulos } \\
\text { linfáticos }+\end{array}$} & \multirow{2}{*}{$\begin{array}{c}\text { Nódulos } \\
\text { linfáticos } \\
\text { x región }\end{array}$} \\
\hline & Pulmonar & Bronquial & R. Faríngeo & Mediastino & Cervical & & \\
\hline $\begin{array}{l}\text { Detección } \\
\text { de ganglios } \\
\text { positivos } \\
\text { por región }\end{array}$ & 5 & 9 & 9 & 8 & 9 & 40 & 115 \\
\hline $\begin{array}{c}\text { Prevalencia } \\
(\%)\end{array}$ & 4,3 & 7,8 & 7,8 & 7,0 & 7,8 & & \\
\hline
\end{tabular}

\subsection{Positividad por raza}

Los nódulos linfáticos que amplificaron para Brucella abortus pertenecen a los mestizos (criollo-Brown Swiss, criollo-Brahman, criollo-Normando, criollo-Gyr), y a los mestizos con Holstein, descendientes del Bos tauros y Bos indicus.
Sin embargo, al evaluar la relación entre la positividad y la raza de los bovinos se observó que ésta no fue significativa (test de asociación de los residuales de Pearson $p=0,1614$ ), con lo cual no hay suficiente evidencia para afirmar que la positividad está asociada con cierta raza (Tabla 3 , Figura 2).

Tabla 3. Detección de Brucella abortus por raza

\begin{tabular}{|c|c|c|c|c|c|c|}
\hline Raza & Cantidad & Porcentaje & $\begin{array}{c}\text { Positivos } \\
\text { a PCR }\end{array}$ & Porcentaje & Negativos & Porcentaje \\
\hline $\begin{array}{c}\text { Mestizos } \\
\text { varios }\end{array}$ & 51 & 44,3 & 11 & 21,6 & 40 & 78,4 \\
\hline M. Holstein & 60 & 52,2 & 6 & 10 & 54 & 90 \\
\hline Holstein & 4 & 3,5 & 0 & 0,0 & 4 & 100 \\
\hline Total & 115 & 100,0 & 17 & 14,8 & 98 & 85,2 \\
\hline
\end{tabular}



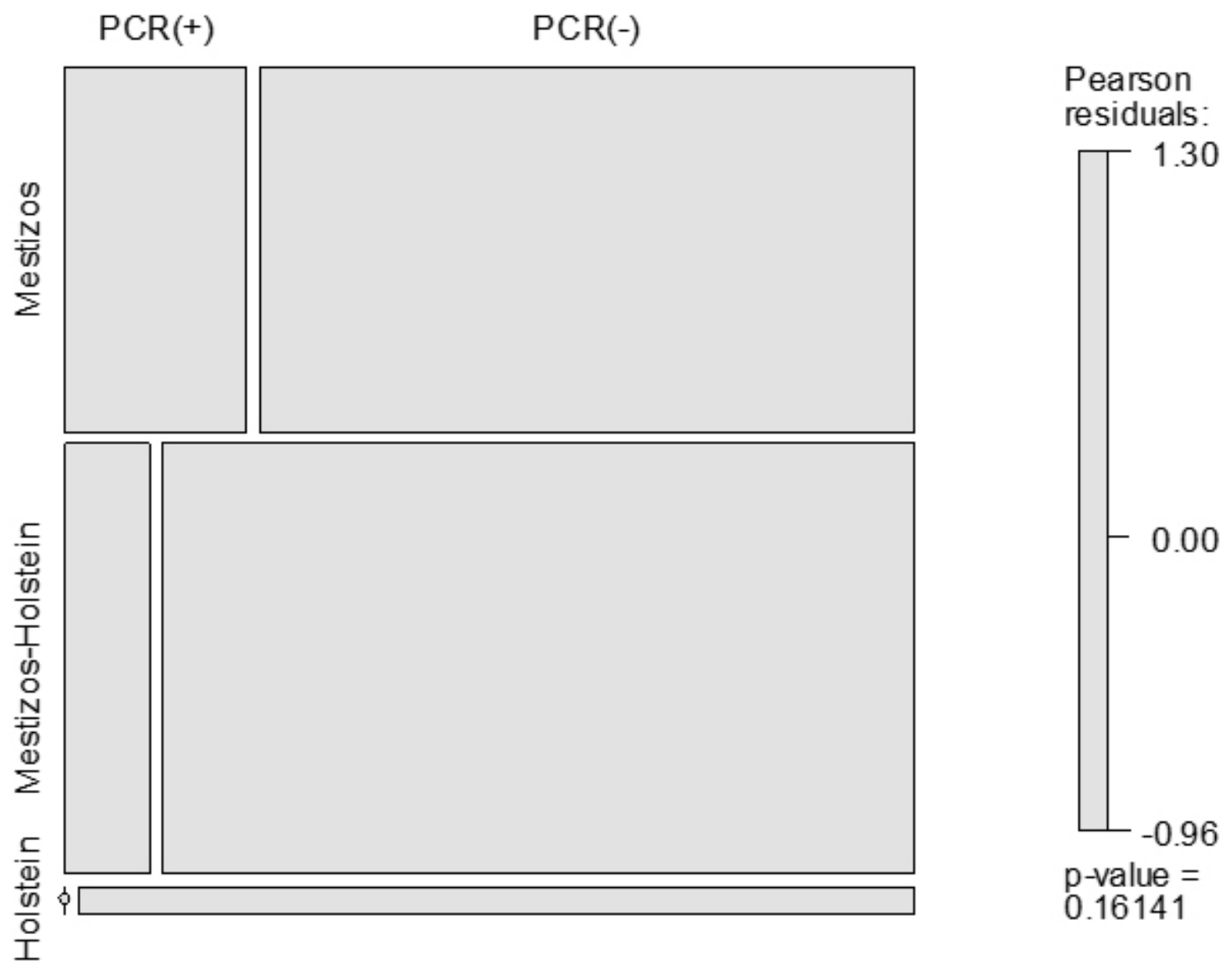

Figura 2. Relación entre la positividad de la prueba PCR y la raza del bovino.

\subsection{Positividad por sexo}

Se muestrearon 78 bovinos macho y 37 hembras bovinas faenados en un camal de Loja, de los cuales 11 machos y 6 hembras respectivamente, se identificaron positivos a la prueba (Tabla 4). Al evaluar la relación entre el sexo del bovino y la positividad de la prueba, no fue significativa $\left(\chi^{2}=0,000293\right.$; g.l. $=1 ; p=0,9863)$, es decir, la bacteria afecta a machos y hembras indistintamente.

Tabla 4. Detección de Brucella abortus por sexo

\begin{tabular}{|c|c|c|c|c|c|c|}
\hline Sexo & Cantidad & Porcentaje & Positivos & Porcentaje & Negativos & Porcentaje \\
\hline Machos & 78 & 67,8 & 11 & 14,1 & 67 & 85,9 \\
\hline Hembras & 37 & 32,2 & 6 & 16,2 & 31 & 83,8 \\
\hline Total & 115 & 100,0 & 17 & 14,8 & 98 & 85,2 \\
\hline
\end{tabular}




\subsection{Procedencia de los animales positivos a la prueba}

Se registró la ubicación del último predio en el que estuvo el animal antes de su faenamiento (Figura 3). De la parroquia El Valle, de los sectores Jipiro, Jipiro Alto, Chinguilanche y El Valle, en la parroquia El Sagrario en el sector Zamora Huayco, de la parro- quia San Sebastián en el sector Dos Puentes, de la parroquia San Lucas en las Juntas plaza de ganado, de Santiago en Cenen y en la parroquia Jimbilla, en Jimbilla, el último predio en donde estuvo el animal, no necesariamente es el sitio en donde el animal se crió. Muchos comerciantes adquieren los animales en las ferias de ganado y los llevan a estos sitios para reponerlos y posteriormente llevarlos a faenamiento.

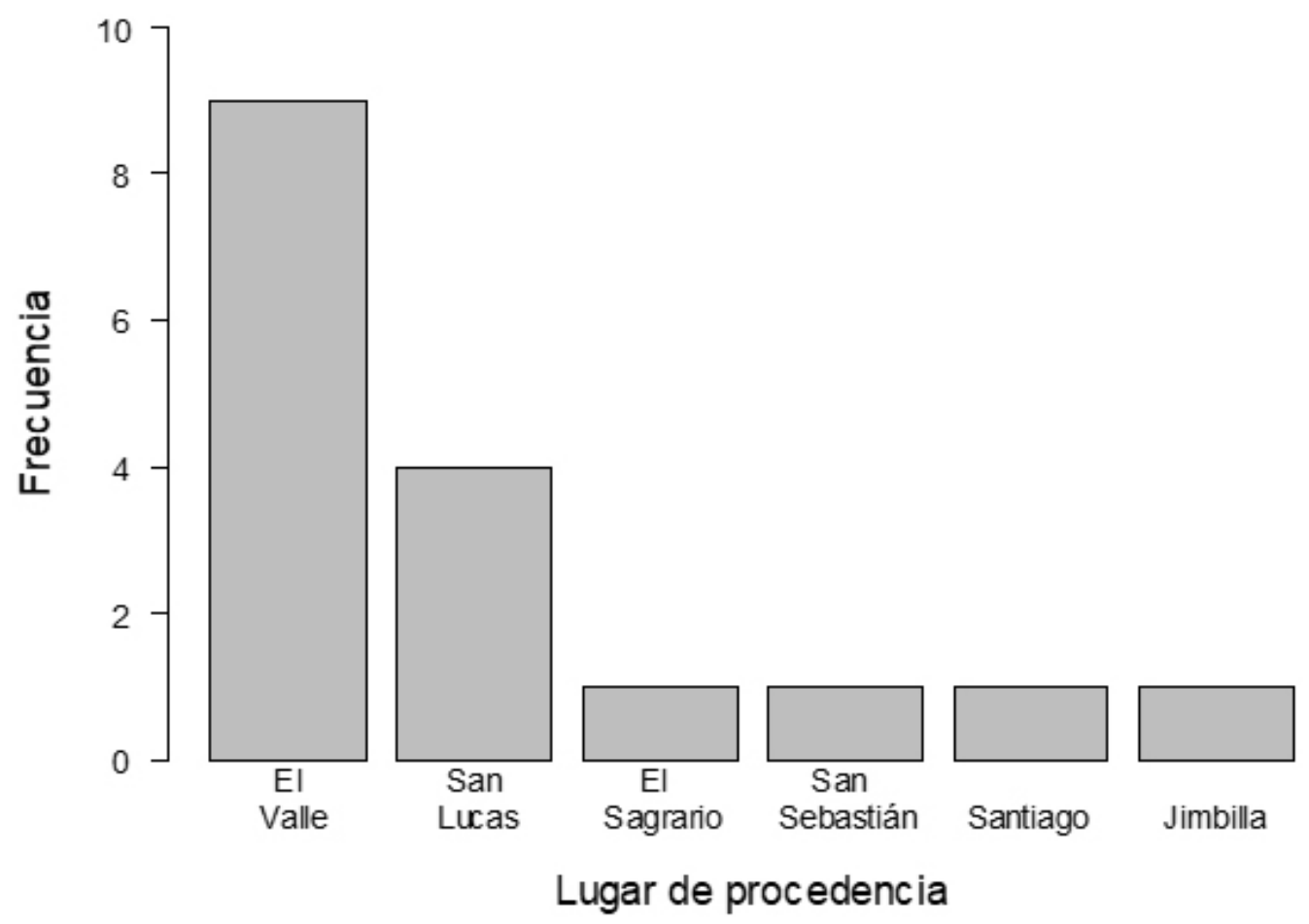

Figura 3. Ubicación del último predio en el que estuvieron los animales positivos a la prueba antes del sacrificio.

\section{Discusión}

Después de la infección, brucela se va a localizar en diferentes nódulos linfáticos, entre ellos los supramamarios, retrofaríngeos y mandibulares; nódulos linfáticos ilíacos internos y externos y útero (Forbes et al., 1996), el objetivo del presente estudio fue confirmar a partir de nódulos linfáticos de bovinos faenados la presencia de la bacteria Brucella abortus, en Loja, de los nódulos linfáticos de las cinco regiones investigadas la presencia de la bacteria no fue detectada por igual; sin embargo, estas diferencias no fueron significativas.

Entre el año 2006 y 2015 en el Ecuador se reportaron 6.806 casos de brucelosis por Brucella abortus, en Pichincha 2.207 y Carchi 993 (OIE, 2017), la seroprevalencia en ganado bovino reportada en Loja por Díaz \& Lamiña (2013) fue del 0 \%, Román-Cárdenas y Chávez-Valdivieso (2016) reportaron el 0,15\%, por pruebas de biología molecular, y Luna (2015) a partir de muestras de nódulos linfáticos y leche de cabra reportaron en Loja la presencia de seis muestras con $\mathrm{Bru}$ cella abortus. En este estudio la presencia de Brucella abortus detectada en ganado bovino faenado en un camal de Loja, mediante la PCR técnica molecular de alta sensibilidad y especificidad es del 14,8 \% (17 casos).

Una de las causas más importantes de la introducción de enfermedades en poblaciones no afectadas, es el ingreso de animales infectados, entre ellas, la adquisición de animales de remplazo de explo- 
taciones cuyo estado sanitario es desconocido o se ha confirmado la presencia de brucelosis (Stringer et al., 2017; Musallam et al., 2015). Por lo que, un factor de la presencia de brucela en Loja podría ser la adquisición de animales de remplazo en provincias de la Sierra, donde se han confirmado casos de brucelosis bovina. En la provincia de Santo Domingo de los Tsáchilas Rodríguez-Hidalgo et al. (2015) reportaron una seroprevalencia de 7,62 \%. Según el Programa Nacional de Control de Brucelosis, las regiones Sierra norte y de la Costa se consideran de alta prevalencia, y el riesgo se incrementa al adquirir animales sin los certificados sanitarios respectivos.

Otro factor que podría influir es que Loja comparte límites con la provincia oriental de Zamora Chinchipe, con la que mantiene fuertes vínculos comerciales de ganado, y en donde se ha detectado por biología molecular la presencia de la bacteria, como lo confirman Ojeda \& Román (2018), en el que un $7,4 \%$ de las muestras analizadas fueron positivas.

\section{Referencias}

Acha, N. P., \& Szyfres, B. (2003). Zoonoses and Communicable Diseases Common to Man and Animals, 3rd edition, vol. 1. Pan American Health Organization (PAHO).

Borba, M. R., Stevenson, M. A., Gonçalves, V. S., Neto, J. S., Ferreira, F., Amaku, M., Telles, E. O., Santana, S. S., Ferreira, J. C., Lôbo, J. R., Figueiredo, V. C., \& Dias, R. A. (2013). Prevalence and risk-mapping of bovine brucellosis in Maranhão State, Brazil. Preventive veterinary medicine, 110(2), 169-176. https://doi. org/10.1016/j.prevetmed.2012.11.013

Boukary, A. R., Saegerman, C., Abatih, E., Fretin, D., Alambédji Bada, R., De Deken, R., Harouna, H. A., Yenikoye, A., \& Thys, E. (2013). Seroprevalence and potential risk factors for $\mathrm{Bru}$ cella spp. infection in traditional cattle, sheep and goats reared in urban, periurban and rural areas of Niger. PloS one, 8(12), e83175. https:// doi.org/10.1371/journal.pone. 0083175

Carlosama, M. (2013) Aislamiento y biotipificación de Brucella spp., de reservorios animales seropositivos, en el centro de faenamiento de Tulcán. Universidad Central del Ecuador.

Chand, P., \& Chhabra, R. (2013). Herd and indivi-
Existen otros factores que representan un riesgo para la presencia de brucelosis bovina, Zambrano-Aguayo et al. (2016), reportan que factores como la raza y el sexo de los bovinos son considerados de riesgo, otros autores también coinciden con estos resultados (Borba et al., 2012; Sanogo et al., 2012; Boukary et al., 2013; Chand \& Chhabra, 2013), sin embargo, en el presente estudio éstos no presentaron relación significativa con la seropositividad de la prueba.

\section{Conclusiones}

Se confirma, mediante la prueba de reacción en cadena de la polimerasa, la presencia de Brucella abortus en ganado faenado en un camal de Loja, la cual no mostró relación, ni con la raza ni con el sexo de los animales faenados, lo que indica que la circulación de la bacteria es independiente de estos factores.

dual animal prevalence of bovine brucellosis with associated risk factors on dairy farms in Haryana and Punjab in India. Tropical animal health and production, 45(6), 1313-1319. https://doi.org/10.1007/s11250-013-0362-y

Cuenca, D. (2013). Estudio epidemiológico de brucelosis humana y animal en la hacienda San Antonio, ESPE-Santo Domingo. Universidad de las Fuerzas Armadas-ESPE.

Díaz, E. (2013). Epidemiology of brucellosis in domestic animals caused by Brucella melitensis, Brucella suis and Brucella abortus. Revue scientifique et technique (International Office of Epizootics), 32(1): 43-51

Díaz, L., \& Lamiña, O. (2013). Determinación de la seroprevalencia y análisis de factores de riesgo de brucelosis en bovinos, en las provincias de Zamora Chinchipe, Loja y El Oro. Universidad Central del Ecuador.

Escobar Cedeño, S., Romero Salguero, E., \& Gualpa Mejía, F. (2017). Geo-referenciación de la prevalencia de brucelosis bovina (Brucella abortus) en Santo Domingo de los Tsáchilas. Revista ESPAMCIENCIA, 8(2), 59-66. 
Forbes, L. B., Tessaro, S. V., \& Lees, W. (1996). Experimental studies on Brucella abortus in moose (Alces alces). Journal of wildlife diseases, 32(1), 94-104. https://doi.org/10.7589/00903558-32.1.94

García, G., Ramírez, J., Hernández, M., Hernández, L., Díaz, E., \& Orozco, H. (2014). Risk analysis of brucelosis in the state of Tlaxcala. Salud Pública de México, 56(4): 355-362.

Luna, L. (2015). Detecting Brucella species in Ecuador. Universidad San Francisco de Quito.

Mayfield, J. E., Bricker, B. J., Godfrey, H., Crosby, R. M., Knight, D. J., Halling, S. M., Balinsky, D., $\&$ Tabatabai, L. B. (1988). The cloning, expression, and nucleotide sequence of a gene coding for an immunogenic Brucella abortus protein. Gene, 63(1), 1-9. https://doi.org/10.1016/03781119(88)90540-9

Ministerio de Salud Pública de la Nación [MSPN]. (2013). Enfermedades Infecciosas. Brucelosis. Guía para el equipo de salud Nro. 12. Dirección de Epidemiología, Ministerio de Salud de la Nación.

Musallam, I. I., Abo-Shehada, M., Omar, M., \& Guitian, J. (2015). Cross-sectional study of brucellosis in Jordan: Prevalence, risk factors and spatial distribution in small ruminants and cattle. Preventive veterinary medicine, 118(4), 387-396. https://doi.org/10.1016/j.prevetmed.2014.12.020

Ojeda Gutiérrez, K., \& Román Cárdenas, F. (2018). Identificación molecular de Brucella spp. en muestras de sangre de ganado bovino de la provincia de Zamora Chinchipe. Centro de Biotecnología, 07, 11-16.

Organización Mundial de Sanidad Animal [OIE]. (2017). Sanidad animal mundial. Obtenido de: https://www.oie.int/es/sanidad-animal-en-el-mundo/sanidad-animal-mundial/

Pappas, G., \& Papadimitriou, P. (2007). Challenges in Brucella bacteraemia. International Journal of Antimicrobial Agents, 30 (Supplement 1), 29-31. Https://doi.org/10.1016/j.ijantimicag.2007.06.011

Pappas, G., Papadimitriou, P., Akritidis, N., Christou, L., \& Tsianos, E. V. (2006). The new glo- bal map of human brucellosis. The Lancet. Infectious diseases, 6(2), 91-99. Https://doi. org/10.1016/S1473-3099(06)70382-6

Paredes S. (2012). Determinar la prevalencia de brucelosis bovina y factores de riesgo en la parroquia Alluriquin, recinto Cristal de Lelia. Universidad de las Fuerzas Armadas-ESPE.

Peña, M. (2011). Identificación y evaluación de riesgos y factores de riesgos que pueden dar lugar a accidentes y enfermedades profesionales en el camal municipal de Azogues. Universidad de Cuenca.

R Core Team. (2020). R: A language and environment for statistical computing. R Foundation for Statistical Computing. Obtenido de https:// www.R-project.org/

Ran, X., Cheng, J., Wang, M., Chen, X., Wang, H., Ge, Y., Ni, H., Zhang, X. X., \& Wen, X. (2019). Brucellosis seroprevalence in dairy cattle in China during 2008-2018: A systematic review and meta-analysis. Acta tropica, 189, 117-123. Https://doi.org/10.1016/j.actatropica.2018.10.002

Resolución 0197. Manual de procedimiento para la vigilancia y control de la inspección ante y post-mortem de animales de abasto en mataderos. 26 de agosto de 2016 (Ecuador).

Resolución DAJ-2013461-0201.0214. Lista de enfermedades de declaración obligatoria. 21 de noviembre de 2013 (Ecuador)

Rodríguez-Hidalgo, R.I, Contreras-Zamora, J., Benítez-Ortiz, W., Guerrero-Viracocha, K., Salcan-Guamán, H., Minda, E., \& Ron Garrido, L. (2015). Circulating strains of Brucella abortus in cattle in Santo Domingo de los Tsáchilas Province-Ecuador. Frontier on Public Health, 3, 45. https://doi.org/10.3389/fpubh.2015.00045

Román-Cárdenas, F., \& Chávez-Valdivieso, R. (2016). Prevalencia de enfermedades que afectan la reproducción en ganado Bovino Lechero del cantón Loja. CEDAMAZ, 6(1), 83-90.

Sanogo, M., Abatih, E., Thys, E., Fretin, D., Berkvens, D., \& Saegerman, C. (2012). Risk factors associated with brucellosis 
seropositivity among cattle in the central savannah-forest area of Ivory Coast. Preventive Veterinary Medicine, 107(1-2), 51-56. https://doi.org/10.1016/j.prevetmed.2012.05.010

Stringer, L. A., Guitian, F. J., Abernethy, D. A., Honhold, N. H., \& Menzies, F. D. (2008). Risk associated with animals moved from herds infected with brucellosis in Northern Ireland. Preventive veterinary medicine, $84(1-2), 72-84 . \mathrm{https}: / /$ doi.org/10.1016/j.prevetmed.2007.11.005
Yousefi-Nooraie, R., Mortaz-Hejri, S., Mehrani, M., $\&$ Sadeghipour, P. (2012). Antibiotics for treating human brucellosis. Cochrane Database of Systematic Reviews, 10, CD007179. Https:// doi.org/10.1002/14651858.CD007179.pub2

Zambrano-Aguayo, M. D., Pérez Ruano, M., \& Rodríguez Villafuerte, X. (2016). Brucelosis Bovina en la Provincia Manabí, Ecuador: Estudio de los Factores de Riesgo. Revista de Investigaciones Veterinarias del Perú, 27(3), 607-617. https://dx.doi.org/10.15381/rivep.v27i3.11995 